\title{
Landscape identity: Implications for policy making
}

\author{
Isabel Loupa Ramos ${ }^{a, *}$, Fátima Bernardo ${ }^{b}$, Sónia Carvalho Ribeiro ${ }^{c}$, Veerle Van Eetvelde ${ }^{d}$ \\ a Instituto Superior Técnico, University of Lisbon, Portugal \\ ${ }^{\mathrm{b}}$ Psychology Department, University of Évora, and CESUR/CERIS, Instituto Superior Técnico, University of Lisbon, Portugal \\ c Centro de Sensoriamento Remoto, Universidade Federal de Minas Gerais, Brazil \\ ${ }^{\mathrm{d}}$ Department of Geography, Ghent University, Belgium
}

\section{A R T I C L E I N F}

\section{Article history:}

\section{Keywords:}

Landscape character

Cohesion

Perception

Landscape change

Landscape policy

\begin{abstract}
A B S T R A C T
Landscape is recognised to be an important asset for people's quality of life and people and the landscape interact in multiple and complex ways. Both in science and policy, this interaction has been dealt with in a fragmented way, depending on the objectives, the disciplinary perspective, as well as the used conceptual backdrop. In this wider framework, landscape identity emerges in policy discourses as a powerful argument to value landscape but it lacks an operationalised framework for policymaking. This paper has two major goals. One is to review the conceptual dialogue between landscape's and people's identity. The other is to identify contents of identity in the landscape (i.e. attributes used to define landscape identity) and the complexity of the identity (i.e. dimensions used to define landscape identity) as a way to increase efficiency in more spatially targeted policies. Above all, this paper discusses how landscape identity has been approached, in order to get an improved understanding of its potential for introducing the landscape concept at multiple levels of governance and how an increased knowledge base might be useful to inform policy making.
\end{abstract}

(C) 2015 Elsevier Ltd. All rights reserved.

\section{Introduction}

Landscape identity is mentioned throughout literature and policy documents as an important asset. The UNESCO World Heritage Convention describes that "Cultural landscapes - cultivated terraces on lofty mountains, gardens, sacred places ... - testify to the creative genius, social development and the imaginative and spiritual vitality of humanity. They are part of our collective identity" (UNESCO, 1992). They also state, that "over half the World Heritage cultural landscapes embody the less tangible characteristic of expressing a group identity" (Fowler, 2006, p. 6). The European Landscape Convention includes already in its preamble that "the landscape contributes to the formation of local cultures and that it is a basic component of the European natural and cultural heritage, contributing to human well-being and consolidation of the European identity". Furthermore the ELC states in the general measures that each country ratifying the convention should "recognise landscapes in law as an essential

\footnotetext{
* Corresponding author. Tel.: +351 218418301.

E-mail addresses: isabel.ramos@tecnico.ulisboa.pt (I.L. Ramos), fatimab@uevora.pt (F. Bernardo), sonia@csr.ufmg.br (S.C. Ribeiro), veerle.vaneetvelde@UGent.be (V. Van Eetvelde).
}

component of people's surroundings, an expression of the diversity of their shared cultural and natural heritage, and a foundation of their identity" (CoE, 2000, article 1a). These are only two examples of policy documents at the European level referring to landscape as part or as the foundation of people's (collective) identity, which is complementary to the idea that landscape can provide perspectives to understand Europe's geography and European environmental meanings and relations (Cosgrove, 1997).

Nevertheless, landscape identity has been used through scientific literature and policy documents in multiple ways. It can either refer to the landscape itself and the features that render its differences, or on how people use the landscape to construct their individual or collective identity, but it can always be understood as the mutual relation between landscape and people. The first perspective has been more systematically used in supporting the assessment of landscape character as a baseline to map landscape types and units and to identify landscape values; whereas the second perspective, even though made explicit in policy discourses, has a more disperse use in research building on the concepts of social representation and place identity as a mean to explore place attachment and sense of belonging. For the purpose of this paper, it is hypothesised that this duality in referring to landscape identity is not random, meaning that there is an interdependency between the two perspectives that needs to be further explored 